\title{
Addressing the Spiritual Needs of People Infected with and Affected by HIV and AIDS in Swaziland
}

\author{
ARNAU VAN WYNGAARD \\ Shiselweni Home-Based Care, Swaziland ${ }^{1}$
}

\begin{abstract}
Researchers seem to be in agreement that spirituality is an important component of the holistic care approach commonly found in palliative care. Shiselweni Home-Based Care (SHBC) is a Faith Based Organization in Swaziland working amongst people with HIV and AIDS in the poorest and most affected areas of the country. They endeavor to restore and build up each client's dignity through the way in which they are approached, not only when giving physical assistance, but also when they address their spiritual needs. This article emphasizes the need for spiritual care as part of the caregiving program and then also illustrates the positive feelings of both the SHBC caregivers as well as their clients as they share some of the experiences encountered during spiritual care.
\end{abstract}

KEYWORDS Swaziland, HIV, AIDS, SHBC, Shiselweni Home-Based Care, spirituality, religion

I felt very happy when my caregiver advised me to repent, because I felt that I was just the same like any other person. There was no stigma. Then the caregiver tried to explain to me, even if I am HIV+ I am just the same as all the others. I do not need to isolate myself. In my mind, in my brain, I just forgave myself, and said, no, I am just the same like all the other people. The shame that I had was removed.

SHBC Client

Arnau van Wyngaard is a Research associate of the Department Science of Religion and Missiology, Faculty of Theology, University of Pretoria, and CEO of Shiselweni Home-Based Care. Address correspondence to Arnau van Wyngaard, P O Box 886, Piet Retief, 2380, South Africa. E-mail: wyngaard@lando.co.za 


\section{INTRODUCTION}

"I would have died," one person said. "I would have killed myself," another answered. Like a refrain these words echoed from the mouths of people who had agreed to be interviewed about their HIV status. They were responding to the question, "What would have happened to you if somebody from Shiselweni Home-Based Care did not come knocking at your door one day, offering their assistance?"

With an adult prevalence rate of $26 \%$ and an antenatal prevalence rate of $42 \%$ (Ministry of Health, 2009, p. 10), Swaziland is the country in the world with the highest HIV infection rate. To make matters worse, $69 \%$ of the population are living below the poverty line (Naysmith, Whiteside \& Whalley, 2008, p. 9). With the economic downturn over the past few years, it is more than probable that this percentage will keep on rising. As the mortality rate rises, the number of incomeearning adults decreases. In the words of Whiteside (2007, p. vii), "In Swaziland, HIV/AIDS is creating a chronic emergency that is permanently altering development. This demonstrates a 'new' disaster that exceeds emergency thresholds and requires a new style of holistic response."

At every level of existence (social, economical and political) a feeling of hopelessness and despondency has taken root amongst many people: Thousands of wives who had previously depended on their husbands to provide money in order to take care of their children, have been forced to take care of their dying husbands and children. Grandmothers, who had prepared themselves to play with their grandchildren, have now become the main caregivers of thousands upon thousands of orphans. Family life is disintegrating.

In each of these spheres there are programs run by government as well as non-governmental organizations doing their best to address these needs. However, despite the extensiveness and availability of these intervention programs, their success rates pivot on the people of Swaziland rediscovering a sense of hope and a reason to live. 


\section{THE SITUATION IN SWAZILAND}

Swaziland is a small, landlocked country bordered by South Africa to the north, west and south, and by Mozambique to the east. It has a population of approximately 1 million people (Naysmith, Whiteside \& Whalley, 2008, p. 9). Although the statistics supplied after the 2007 census (which indicated a decrease in the population from 929,718 in 1997 to 912,229 in 2007) might be inaccurate (Henry J. Kaiser Family Foundation, 2008), even the adapted figure of 1,018,449 (UNAIDS, 2010 , p. 9) is still much lower than expected, attributed primarily to deaths resulting from the AIDS pandemic. In 2006 it was projected that the number of orphans and vulnerable children (OVC) would rise to 200,000 by 2010 (Naysmith, Whiteside \& Whalley, 2008, p. 9).

With one HIV Counseling and Testing (HCT) site per 6,180 people versus one church per 183 Swazis (Root \& Van Wyngaard, 2011, p. 2), it is clear that the power that is locked up in churches possess vast, untapped capabilities to render crucial services such as motivating people to be tested, HCT, encouraging people to remain on antiretroviral therapy (ART) and generally bringing life, hope and dignity back into communities. "Dignity-conserving care comprises not only what one does to patients, but how one sees patients.... When dying patients are seen, and know that they are seen, as being worthy of honour and esteem by those who care for them, dignity is more likely to be maintained" (Chochinov in Sinclair, Pereira \& Raffin, 2006, p. 473).

In Swaziland, where spirituality plays such an important role in almost every aspect of the daily lives of people, the great variety of churches spread across the country are particularly suited and strategically placed to address the spiritual needs of people:

The churches have strengths, they have credibility, and they are grounded in communities. This offers them the opportunity to make a real difference in combating HIV/AIDS... bringing healing, hope, and accompaniment to all affected by HIV/AIDS (World Council of Churches, 2001, p. 3). 


\section{SPIRITUALITY IN SWAZILAND ${ }^{2}$}

"Spirituality involves humans' search for meaning in life" (Tanyi, 2002, p. 500). In Swaziland, this search for meaning traditionally finds expression in various rites and rituals marking critical moments in a Swazi's life. An exploration of these rites and rituals indicate a deep connectedness to nature, to the living as well as to those who have passed through death from the present world to the world of the ancestors.

To many Swazis, Mkhulumchanti ${ }^{3}$ created the earth and handed it over to the ancestors who act on His behalf ruling over the earth. The Swazi perspective of their guardians is one of abject fear. This fear typically clouds all other issues within the Swazi kingdom. This dread of the ancestral spirits is further instilled through a variety of cultural rituals. These spiritual rites take place throughout a Swazi's life, beginning when the child is born. Immediately after birth, the child is ritually dedicated to the ancestors for protection by burning herbs, snake skin and animal hairs. Then a small incision is made on the hairline on the forehead, the neck and each joint, and ash is rubbed into the cuts to protect it from evil. Now a length of string is tied around the waist. This string has a twofold function: to measure the growth of the baby and to ward off any evil. After four months the child is shown to the moon and symbolically introduced to the world of nature. Babies and young children also wear a necklace to protect them from evil.

When the child reaches puberty, a further rite takes place at which time goatskin is made into a belt or a bracelet that is affixed to the waist or wrist to prevent sexual dreams caused by an evil spirit. When a woman gets married she is forced to cry out loudly in a ceremony so that her new family's ancestors will know that she is a part of the family. If the elder of the homestead or a 'first born' dies within the family, a cry goes up. This cry is said to alert the ancestors of the bereavement and they will await a report by the family elder of the deceased who will soon be joining them. To revere the passing of the person, a cow is slaughtered. The cow will be central in a ritual that brings back the spirit of the dead, in a feast that ends all active mourning. Before the body is buried, the

I gratefully acknowledge the research done by Neville Curle in this regard for his $\mathrm{PhD}$ thesis.

3 The First Ancestor or God 
mourners take it through the cattle byre where the ancestors dwell. There, they stop and "rest", acknowledging the long journey that the deceased is taking. Finally, the person is handed over to the ancestors by the eldest male relative (or elder aunt if no elder male is living) within that clan.

Christianity was introduced into Swaziland through the Methodist church in 1845. The Lutheran Church followed in 1887, and the Roman Catholic Church in 1913. In an attempt to retain the traditional spirituality of the Swazis, a number of independent churches were founded between 1880 and 1920 throughout the country, often distinguished by a high degree of compromise with polygamy, ancestor veneration and appeasement sacrifices (Johnstone \& Mandryk, 2001, p. 604).

Officially, all religions in Swaziland are seen as being equal. However, Christianity is by far the most predominant faith in the country. According to Johnstone \& Mandryk (2001, p. 603) 82\% of the total population describe themselves as Christian, of which $74 \%$ (61\% of the entire population) are from the independent churches.

\section{SHISELWENI HOME-BASED CARE}

Church communities have generally been slow to get involved with the AIDS crisis. In 2005 the pastor and the members of the Swaziland Reformed Church (Shiselweni Congregation), situated in the poorest and most vulnerable southern (Shiselweni) part of Swaziland, formulated the vision "To become the hands and the feet of Christ in the communities surrounding the church" through a home-based caring program, known as Shiselweni Home-Based Care (SHBC). Although individuals and small bands of volunteers have tried to address these problems in the past, they often become discouraged because they feel that they have no moral support. Instead of merely implementing something on their own, SHBC took hands with people who were already doing this essential work within the communities and brought them together into an organization which not only has a voice, but was able to build communities with a caregiving mindset - probably one of the most important differentiating factors when SHBC is compared with other organizations working within the field of HIV and AIDS in Swaziland. 
After initially training 36 people in an area known as Dwaleni, the group of volunteers, all working without any salary, started reaching out to members of the community in need of care and support, thereby establishing a nucleus of caregiving skills within those communities. Although most of the clients are women and vulnerable children, this service is rendered regardless of gender or faith. After one year the group started expanding as word of their compassion spread throughout the region, and at present 819 volunteers (779 female and 40 male), many of whom are HIV-positive themselves, form part of this homebased caring program in thirty different rural communities. More than 2700 clients are cared for by this group of volunteers (Van Wyngaard, 2006).

\section{THE SPIRITUAL CARE OF THE SICK}

It is widely accepted that palliative care is committed to holistic care. This implies the physical, social, psychological and spiritual care of patients (Wasner et al., 2005, p. 99). However, there seems to be a growing interest in the spiritual care of the sick. While there had been some interest in the topic prior to 1990, much more has been written about spirituality and health care since then (Sinclair et al., 2006, p. 465-466).

From the many articles published on the topic of spirituality in regard to palliative care, it is clear that it is extremely difficult to define the exact meaning of the term (Wasner et al., 2005, p. 99-100; Gordon \& Mitchell, 2004, p. 646). The Association of American Medical Colleges formulated the following definition (quoted in Puchalski, 2002, p. 291):

\footnotetext{
Spirituality is recognized as a factor that contributes to health in many persons. The concept of spirituality is found in all cultures and societies. It is expressed in an individual's search for ultimate meaning through participation in religion and/or belief in God, family, naturalism, rationalism, humanism, and the arts. All of these factors can influence how patients and health care professionals perceive health and illness and how they interact with one another.
}

Gordon \& Mitchell (2004, p. 646) remark that spiritual care is usually administered in a one-to-one relationship, focused on the person being 
cared for, while making no assumptions about personal conviction or life orientation. Spirituality addresses human beings' need to seek and find a meaning within their current suffering which allows them to make sense of that situation. Victor Frankl wrote that "man is not destroyed by suffering; he is destroyed by suffering without meaning" (in Puchalski, 2002, p. 290). The spiritual aspect of caring therefore helps give meaning to people's suffering. Sinclair et al. (2006, p. 470) analyzed the literature published on the topic of spirituality within palliative care published from 1960 to 2005 and concluded that:

\footnotetext{
...half of the articles defined spirituality from what could be described as a humanist perspective focussing on the term "meaning" that in turn differentiated "spirituality" from "religion." In focusing on "meaning," this also resulted in spirituality being defined very individualistically, with minimal mention of "other."
}

Other writers identify topics such as the search for hope, the need for companionship, the question about the existence of God, life after death and simple presence during a difficult and sometimes frightening journey as further objectives of spirituality in palliative care (Kellehear, 2000, p. 151; Hermsen \& Ten Have, 2004, p. 354).

\section{SPIRITUALITY AND RELIGION}

Although spirituality is not necessarily the same as religion and may ask different questions than those posed by religion, religious care should always be spiritual (Gordon \& Mitchell, 2004, p. 646). Religion is generally considered to be "correlated to an organized faith system, beliefs, worship, religious rituals, and relationship with a divine being" (Sinclair et al. 2006, p. 467). In the available literature on spirituality and palliative care, both the terms "spirituality" and "religion" often refer to Christian or Judeo-Christian traditions (Sinclair et al. 2006, p. 467). Doyle (quoted in Hermsen \& Ten Have, 2004, p. 254-355) says, "By religious, we mean practices carried out by those who profess a faith. By practices, I am thinking of prayer, Bible reading, the receiving of sacraments, the discipline of times of devotions, and so forth."

Much of the available literature on the role of religion in palliative care, suggest that people with strong religious beliefs have less anxiety, death depression, and death distress, radiating a source of inner strength and 
peace. The fear of dying is often absent because of a belief in an afterlife and the expectation of a reunion with loved ones who have died before them. Furthermore, relatives who have a strong religious conviction and whose loved ones had recently died, also seemed to come to terms with their death sooner than those with little or no religious conviction, although this is not necessarily related to belief in an afterlife (Sinclair et al. 2006, p. 473; Hermsen \& Ten Have, 2004, p. $355)$.

On the other hand, research also indicates that faith can have a negative influence on people faced with a terminal disease. Disillusionment with a "loving" God who could allow this to happen may follow the disclosure of the person's health situation, leading to a spiritual crisis where the presence or existence of God may be questioned. It is also possible that some patients may feel that the illness has been sent as a punishment from God, especially if guilt is present over past sins (Hermsen \& Ten Have, 2004, p. 355).

\section{SPIRITUALITY AND HOPE}

There is a strong connection between spirituality / religious beliefs and hope. Research done to determine the feeling of hopelessness in patients with advanced AIDS (Rosenfeld et al., 2004) revealed that a pessimistic view of the future was the highest reason for suicidal ideation (Rosenfeld et al., 2004, p. 51). Various researchers however noted a strong connection between hope and a person's belief system. The hope referred to is not a hope for survival, but rather coming to peace and finding meaning in life despite the existing circumstances (Sinclair et al. 2006, p. 472).

In order for hope to occur, it is often necessary to go through a process of hopelessness and denial. Centers (in Sinclair et al. 2006, p. 472) suggests that in doing so it is possible to arrive at a far deeper understanding of hope - a more holistic understanding of hope. This would imply that hope is not something that one should rush to too quickly, as this may circumvent the feeling of hopelessness and despair that often needs to be wrestled with before hope in its fullness can be experienced. The caregiver is in a powerful position to generate hope through building a trusting relationship with the patient, demonstrating a 
willingness to listen and conveying acceptance of them as they are (Hermsen \& Ten Have, 2004, p. 355).

\section{SPIRITUALITY AND SHBC}

SHBC is a Christian organization reaching out to a variety of communities in an attempt to help community members take care of their sick neighbors and family members. Even though SHBC is Christian in its ethos, it does not stipulate that all caregivers wishing to be part of the organization should be Christian in their faith, and caregiving services are rendered to any person in need, regardless of gender or faith.

Very little research has been done about the role of spirituality in the life of the caregiver. Almost all research done about spirituality and palliative care focus on the clients. Sinclair et al. (2006, p. 468-469) found very few researchers who had focused on this topic and remark, "It seems somewhat ironic that we, as caregivers, recognize the importance of holistic care for our patients (spiritual, psychological, social and physical), yet we do not see the importance in living out this philosophy personally as is evident in the lack of research on the topic" (2006, p. 469).

In an attempt to determine the effectiveness of SHBC's modus operandi, it was therefore decided to conduct semi-structured openended interviews with a substantial number of the coordinators, homebased caregivers as well as clients of SHBC.

\section{RESEARCH METHODOLOGY}

Data used for this article are derived from a qualitative study that was designed to explore SHBC caregiver and client experiences. ${ }^{4}$ On three short-term field visits between 2009-2011, face-to-face semi-structured open-ended interviews were conducted with care coordinators $(\mathrm{N}=13)$, who oversaw an estimated 455 caregivers, caregivers $(\mathrm{N}=7)$ as well as SHBC clients $(\mathrm{N}=79)$. The SHBC's program coordinator as well as the organization's CEO (author of this article) were also interviewed.

4 See Root \& Van Wyngaard 2011, for en in-depth discussion of the study methodology. 
The aim of the caregiver study was to explore caregiver motivations, perceptions of clients' needs, caregivers' HIV-related and other care practices and perceptions of the role of Christianity in home-based caregiving (Root \& Van Wyngaard, 2011). Where caregiver respondents were unable to communicate fluently in English, a translator was used to interpret the questions and responses. With the permission of the respondents, all interviews were audio recorded and later transcribed in order to analyze the responses. A grounded theory approach was used to extract key themes from caregiver interview data.

Face-to-face semi-structured questionnaires were also conducted with clients to better understand their experiences of SHBC care and support. ${ }^{5}$ The research questions were operationalized in terms of the following variables: clients' critical needs; social networks for meeting those needs; perceptions of caregiver practices; HIV/AIDS communication with caregivers; family reactions to the caregiver; personal religiosity; and the significance of caregivers' Christian affiliation. Research procedures were approved before research commenced by Baruch College's Human Research Protections Program, City University of New York (USA).

\section{DATA ANALYSIS}

Using the transcriptions made of the interviews, specific thematic categories were identified as the open-ended responses to the interviews were analyzed. Of the 46 questions used during the interviews, six were specifically relevant for my research on the effectiveness of addressing the spiritual needs of people living with HIV and AIDS. These questions were the following:

- In your view, would you say the care supporters are religious people, or health people, or both?

- Is it comfortable talking about HIV/AIDS with the care supporters?

- Are there religious aspects to the support the caregiver provides?

- Can you tell me, is it important to you that a care supporter be a Christian, or does it not matter?

- Have your own religious feelings changed since the care supporter started visiting? 
- If yes, do you feel more or less religious?

The responses to the above questions were further analyzed to detect trends in the answers given.

\section{CONNECTING WITH CLIENTS ON A SPIRITUAL LEVEL}

Part of the interview focused on the role of spirituality in the lives of the caregivers. Asked whether it is important for a caregiver to be a Christian, one respondent answered, "You can't do it without being a Christian because at times you find problems with your client. A sick person becomes one with you, so if you are not a Christian you can't bear it. If you're a Christian it becomes easier to bear it." ${ }^{, 6}$ Another caregiver answered, "I think it's not easy for a person who is not a Christian to be a caregiver, especially as caregivers we are not getting any money from caregiving. Some people who are not Christians will not work like this, because we are giving our strength, we are giving our love to the people." A third one answered, when asked whether it is possible to be a caregiver without being a Christian: "If you're not a Christian? How? How can I give the care? I'm asking you. Is it possible to be a caregiver if you're not a Christian? I don't think it is possible."

In another instance, when pressed for more detail about the importance of religion in her life, one of the caregivers answered:

It's because you have to be faithful. If you give me something to give my clients [e.g., food], I must do that. If I'm not faithful, I will eat it myself. If I tell my clients, 'I will come to you at nine o'clock', [and I'm not there], the client will [doubt me]'. The rhetoric of religion became a discourse of love, and then a care practice, since the care work itself could be off-putting. 'You can't be a caregiver when you don't have love', she insisted. 'You can't, because some clients are so sick they can't go to the toilet, so you have to help them' (Root \& Van Wyngaard, 2011, p. 183).

Of the 20 caregivers and care coordinators interviewed, only one indicated that being a Christian would not necessarily make one be a better caregiver. When asked what would then motivate such a caregiver to continue with the work, she answered: "It's that, if you're

6 Unless otherwise indicated, the responses quoted in the article were taken verbatim from the anonymous transcriptions of the interviews. 
visiting the homestead, you don't go alone. You go in two's or three's. When you are going together with the other one who is not a Christian you can see that he also loves, but the difference is that he didn't accept Jesus Christ."

The research strongly suggests that the majority of the caregivers feel that their faith helps them handle the difficult challenges they face on a daily basis as they care for their clients. "My faith is keeping me going, because I believe I'm the temple of God" (Root \& Van Wyngaard, 2011, p. 184).

Another caregiver mentioned that community members tend to put greater trust in Christian caregivers, having experienced that things shared with the caregivers will remain confidential.

I told the man, "I have a plan [so you can tell your wife you're HIV positive]". I knew the husband and wife each was positive, and that the other didn't know. I told him I'd come to their home one Saturday with a slaughtered chicken and ask her to cook it with porridge . . . I visited and we all told stories. Then the man said, "Now, my wife, what if I told you I'm HIV positive?" She said, "I would just accept you as you are, because you are still a human being". I said, "This is your chance". So he said, "I am HIV positive". She said, "I'm also positive", and went to get her handbag. "You see this? I never, ever put it down, because it has my tablets [antiretroviral therapy]". My heart was so sad, because the man had hidden his tablets under a tree outside the homestead. He dug a hole and everyday he'd go to the tree [to take the ART in secret] (Root \& Van Wyngaard, 2011, p. 174$175)$.

In another instance a caregiver shared a similar story of how her client informed her that she was HIV-positive, but asked the caregiver not to tell her husband about his wife's condition. A few weeks later, as the caregiver was leaving the homestead after visiting her client, the client's husband was waiting for the caregiver at the gate. He told the caregiver that he was not feeling well. The caregiver advised him to go to the clinic and ask them to test his blood to determine the cause of his illness. When the caregiver returned to the homestead a few days later, the husband was once again waiting for her outside the home and informed her that he had been to the clinic and that he is HIV-positive. Unaware of the agreement of confidentiality between his wife and the caregiver, he then asked the caregiver to keep this information a secret 
and not to reveal it to his wife. (Some time later the caregiver facilitated a conversation between the husband and wife, at which time they admitted to each other that they were both HIV-positive.)

SHBC caregivers are expected to treat their clients with dignity and respect. Regardless of their own spiritual convictions, the spiritual needs of the client will always dictate how the spiritual connection is made. This is clearly illustrated through the answers given by the caregivers to the questions on how they approached their clients when requesting permission to pray with them or to read a passage from the Bible:

\footnotetext{
When I come to the homestead I introduce myself and make a relationship with them. When I see that the family do appreciate me, so I will say to them, "I'm a caregiver - also a born-again Christian. Before I leave I would like us to pray so that God can make our friendship grow more and more. And as the Bible says we must love our neighbors," and I tell them that as neighbors we must share the love of God and we do that by praying; then if they do accept that, we pray, but if they say "No, in this home we don't pray," then I say "Oh, thank you," but at my home I will pray for them.
}

The same pattern appeared in the responses of other caregivers who were interviewed, "For the first time I ask permission just to pray first, then ask permission to just read some verses from the Bible." "After I introduce myself then I'll ask the client the name, surname of that homestead. Yes. Then after that introduction I'll say, 'I'm a Caregiver, visiting the homestead in the community - the sick ones.' Yes. Then after that I'll ask permission for praying. Then after the praying I will ask to read from the Bible."

When we first visit the family we mention all the things that we are doing. Since we meet they know we are doing this and this and this. Usually we ask if they are Christians. Some they will say, "Yes, we are Christians." Most will say, "Yes, we are also Christians. We like praying, reading the Bible. And Evangelism. We like it." At times they say, "Oh, I'm not a Christian".

But we still go back to care for them even if they are not Christian.

The objectivity of the caregivers regarding the spiritual care of their clients is further illustrated through one of the SHBC caregivers who is from the Muslim faith. She comes from a small rural community where she is the only Muslim. When asked how she addresses the spiritual needs of her Christian clients, she answered, "I share the Bible with 
them, because we as Muslims we are using the Qu'ran but there are some verses in the Qu'ran which are quoted in the Holy Bible. So I read the Bible to them - it doesn't matter. I don't care. I'm okay with that."

\section{SPIRITUALITY AND THE SHBC CLIENT}

During January 2011, 79 clients were interviewed about various aspects of the care they were receiving from SHBC. Amongst others they were requested to reveal their perceptions on spirituality / religion as they were receiving health care. Asked how they perceived the SHBC caregivers, i.e. religious people, health people or both, $86 \%$ of the respondents indicated that the caregivers fulfilled both roles.

When asked whether there were religious aspects to the support the SHBC caregivers provide, most of the respondents referred to the caregivers supporting them through prayer and through Scripture reading. However, some elaborated further by mentioning the physical help they were receiving as proof of the caregivers' faith, "Yes. They do things that shows that they are Christian. Like, if we are sick, they clean us. They teach us this is not a death sentence. God is there, He still loves us." Another answered: "She helps me by all means," meaning the caregiver does whatever is necessary to help the client.

Of the 79 clients interviewed, 12 specifically referred to confidentiality being one of the main reasons why they preferred their caregivers to be Christians, thereby confirming the perception held by the caregivers that this is indeed one of the main considerations taken into account when a client seeks help from a caregiver: "I don't want to tell my stories to a non-Christian because she will go about talking my stories outside." Another responded, "The caregiver [that is a Christian] doesn't move from door to door", (i.e., she keeps the secret).

Furthermore, $77 \%$ of the clients interviewed indicated that their own religious feelings had changed since the SHBC caregiver started visiting. Although only 5 of the interviewed clients indicated that they had become Christians for the first time after the caregivers had spoken to them, for most the presence of their Christian caregivers had other, and possibly unpredictable advantages. It is not surprising that a number of clients focused on having a more positive outlook on the meaning of life due to the spiritual support they were getting from their caregivers. 
One client said that she felt "revived" every time her caregiver visited her, read from the Bible and prayed with her. A few indicated that they felt "uplifted" after their caregivers had been to their homesteads. Others felt "more motivated". For some, however, their faith in God had the very practical effect of helping them to remain on ART: "I am encouraged because God helps me to not stop taking pills." For others, this was leading to a new life-style: "I've been encouraged by the caregiver not to commit adultery." Many indicated that the caregivers had encouraged them to place their hope in God: "When they come, pray, and encourage me to believe in God, that whenever I take ARV, I must also pray to God because He is the one who cares about our lives." Another one reacted: "My caregiver encourages me to read the Bible. She quotes verses of when Jesus was preaching and healed a woman. She also told me of the story of Job. That encourages me because even if my children stigmatizes me, God still loves me."

\section{CONCLUSION}

In many ways, Swaziland has become a country with little hope. Economical and political instability will probably be part of the history of Swaziland for many years to come. But for traditional people living in the rural parts of Swaziland, who have no source of income and who will have little personal advantage in a new political order, the one thing which will continue to play a role in their lives, is the existence of HIV and AIDS.

In the midst of feelings of hopelessness and despair, a responsible and dignified approach by caregivers towards those in need of help can mean the difference between life and death, as clearly indicated by the $53 \%$ of participants who indicated that they would have died, a few from suicide, if the care supporters had never come into their lives (Root, 2011, p. ii).

Starting in 2008, a simple yet highly effective Monitoring and Evaluation system was implemented for use by all SHBC caregivers, indicating the following results of the program:

From 2008 - 2011:

- 13,351 people were referred for HCT

- 7,893 were referred for ART 
From the following statistics taken from 2008 to 2011, it can be seen that the death rate of SHBC clients in the rural communities of Shiselweni has dropped drastically from $35.3 \%$ to $14.8 \%$ - probably the most significant proof of the positive impact of the SHBC's holistic approach.

- 2008: 621 of 1,758 clients died $(35.3 \%)$

- 2009: 506 of 2,397 clients died (21.1\%)

- 2010: 448 of 2,577 clients died (17.4\%)

- 2011: 395 of 2,665 clients died (14.8\%)

Caregivers increasingly realize the importance of spiritual care as part of the holistic support offered to people with HIV and AIDS. Spiritual care which conserves the dignity of each client and their families, can help those who would normally have suffered through stigmatization and guilt imposed by themselves or family and community members, to acquire hope in an otherwise seemingly hopeless situation.

Victor Frankl wrote: "Even the helpless victim of a hopeless situation, facing a fate he cannot change, may rise above himself, may grow beyond himself, and by so doing change himself" (1992, p. 147).

The interviews done in Swaziland to determine the effectiveness of the organization's holistic approach, with the inclusion of the spiritual aspect when taking care of those with HIV/AIDS, confirms that this is the key for caregivers and clients alike to rediscover hope and the meaning of life in a country where many have lost these basic skills of survival.

\section{REFERENCES}

Curle, N, 2012. A Theological Evaluation of the Patriarchalistic understanding of Authority and Submission in Marriage contextualized within the Kingdom of Swaziland. Johannesburg: SATS.

Frankl, V, 1992. Man's Search For Meaning: An Introduction To Logotherapy. Boston: Beacon Press. 
Gordon, T and Mitchell, D., 2004. A competency model for the assessment and delivery of spiritual care. Palliative Medicine. 18, 646-651.

Government of Swaziland, 2006. National Plan of Action for Orphans and Vulnerable Children 2006-2010. Mbabane: Government of the Kingdom of, Swaziland.

Hegarty, M.M. Abernethy, A.P. Olver, I. and Currow, D.C., 2011. Former Palliative Caregivers Who Identify That Additional Spiritual Support Would Have Been Helpful in a Population Survey. Palliative Medicine. 25:3, 266-277.

Henry J. Kaiser Family Foundation, 2008. HIV/AIDS Epidemic Affecting Swaziland's Population, Experts Say. Retrieved from http://www.thebody.com/content/art44574.html

Hermsen, M.A. and Ten Have, H.A.M.J., 2004. Pastoral Care, Spirituality, and Religion in Palliative Care Journals. American Journal of Hospice and Palliative Medicine. 21:5 (September/October), 353-356.

Johnstone, P. and Mandryk, J., 2001. Operation World. Cumbria: Paternoster Lifestyle.

Kaplan, K.O. and Peres, J.R., 2002. Means to a Better End: A Report on Dying in America Today. Washington: Last Acts.

Kellehear, A., 2000. Spirituality and palliative care: a model of needs. Palliative Medicine. 14, 149-155.

Kuin, A. et al., 2006. Spiritual Issues in Palliative Care Consultations in the Netherlands. Palliative Medicine. 20, 585-592.

Ministry of Health, 2009. The Health Sector Response to HIV and AIDS Plad: 2009 - 2014. Mbabane: Government of Swaziland.

Naysmith, S. Whiteside, A. and Whalley, A., 2008. Rethinking Swaziland's HIV/AIDS Epidemic. Canadian Journal of Public Health. 99 (May - June), 8-10.

Neilson Ken, 2004. Swaziland: Land of Contrast. Sussex: World Hope (Canada).

Puchalski, C.M., 2002. Spirituality and End-of-Life Care: A Time for Listening and Caring. Journal of Palliative Medicine. 5:2, 289-294.

Puchalski, C.M. Dorff, E. and Hendi,Y., 2004. Spirituality, Religion, and Healing in Palliative Care. Clinics in Geriatric Medicine. 20:4, 689-714.

Rodenfeld, B. Gibson, C. Kramer, M. and Breitbart, W., 2004.

Hopelessness and Terminal Illness: The Construct of Hopelessness 
in Patients with Advanced AIDS. Palliative and Supportive Care. 2, 43-53.

Root, R, and Van Wyngaard, A., 2011. Free Love: Religion and Community Home-based Care in Swaziland. Global Public Health. DOI:10.1080/17441692.2011.581675, 1-18.

Root, R., 2009. Being Positive in Church: Religious Participation and HIV Disclosure Rationale among People living with HIV/AIDS in Rural Swaziland. African Journal of AIDS Research. 8:3, 295-309.

Root, R., 2010. Situating PLWHA Experiences of HIV-related Stigma in Swaziland. Global Public Health. 5:5, 523-538.

Root, R., 2011. "That's When Life Changed”: Client Experiences of Church Run Home-based HIV/AIDS Care in Swaziland. Retrieved from http://www.shbcare.org/images/stories/Documents/ChurchRunHBC .HEARD.Root.pdf

Sinclair, S. Pereira, J. and Raffin, S., 2006. A Thematic Review of the Spirituality Literature within Palliative Care. Journal of Palliative Medicine. 9:2, 464-479.

Steinhauser, K.E. et al., 2000. Factors Considered Important at the End of Life by Patients, Family, Physicians, and Other Care Providers. JAMA. 284:19 (November), 2476-2482.

Tanyi, R, A., 2002. Towards clarification of the meaning of spirituality. Journal of Advanced Nursing. 39:5, 500-509.

UNAIDS, 2010. Swaziland 2010 UNGASS Report. Geneva: UNAIDS.

Van Wyngaard, A., 2004. Why are we losing the battle against AIDS? REC Focus. 4:1 (February), 89-97.

Van Wyngaard, A., 2006. On Becoming the Hands and Feet of Christ in an AIDS-ridden community in Swaziland. Verbum et Ecclesia. 27:3, 1095-1109.

Wasner, M. Longaker, C. Fegg, M.J. and Borasio, G.D., 2005. Effects of Spiritual Care Training for Palliative Care Professionals. Palliative Medicine. 19, 99-104.

Whiteside, A and Whalley, A., 2007. Reviewing 'Emergencies' for Swaziland - Shifting the Paradigm in a New Era. Durban: HEARD.

Whiteside, Alan et al., 2006. The Socio-Economic Impact of HIV/AIDS in Swaziland. Durban: HEARD.

World Council of Churches, 2001. Plan of Action: The Ecumenical Response to HIV/AIDS in Africa. Global Consultation on the Ecumenical Response to the Challenge of HIV/AIDS in Africa. 110. 